\title{
Smart London
}

\author{
Michael Batty, Ed Manley, Richard Milton and Jon Reades
}

\section{Technology, information and cities}

Suddenly, after sixty years of dramatic advances in digital computing where computers are now being embedded and networked in every imaginable artefact including ourselves, cities for the first time are becoming automated. Cities in fact are turning into computers with enormous and unprecedented effects on how we behave and function within them. At every stage of the computer revolution since the 1940s, we have been reminded that the computer is a universal machine. The father of modern computing Alan Turing in 1948 stated that "A man provided with paper, pencil, and rubber, and subject to strict discipline, is in effect a universal machine" (Turing, 1948). This idea, reduced to its bare essentials and embodied in silicon, set the world on its way to our current age where computers are more numerous by far than their users.

The size and scale of cities is intrinsically linked to their technology. Cities were barely able to grow beyond one million in size before mechanical technologies were invented at the beginning of the industrial revolution, and only then was it possible to ever envisage more than a handful of cities of this size. In fact at any one time there was rarely more than one such city. Rome for example, grew to about this level but it was sustained by an enormous empire which at first was held quite tightly together by highly disciplined communications bolstered by the army. After Rome, Nanjing and Beijing reached similar sizes in the $6-7^{\text {th }}$ centuries while London only reached one million in 1800 , before industrial technologies began to revolutionise communications.

Once mechanical technologies became pervasive, then cities began to grow, first through mass transit based on rail and streetcar which opened up and spread their hinterlands and then through the automobile. Cities for the first time reached ten million in the mid-20 $0^{\text {th }}$ century, New York being the first, and they also grew in the vertical direction, again due to new technologies based on the steel frame and the elevator. The great conundrum of course is what will electrical technologies do to the size and shape of cities? For over 100 years, the telephone has been key to linking places together but now with email and various social media, web-based interactions are becoming near

How to cite this book chapter:

Batty, M, Manley, E, Milton, R and Reades, J. 2013. Smart London. In: Bell, S and Paskins, J. (eds.) Imagining the Future City: London 2062. Pp. 31-40. London: Ubiquity Press. DOI: http://dx.doi.org/10.5334/bag.d 
universal, offering prospects of remaining social and economically connected anywhere, everywhere and at any time but always in the context of large scale physical disconnection. Although we have little clue as yet of what this will mean, it must have an important impact in the next fifty years on the size and shape of our cities and how we organise ourselves spatially.

London of course is a fulcrum in these changes. For 200 years or more, it has been a global city and it is rapidly becoming a city-state in its own right, spreading far beyond its physical borders and in some sense, being the core of a highly integrated urban system in the UK, and beyond. Increasingly we need to think of such a city as a city of flows manifest at many scales from the local to the global, envisaging its future as one in which networks will dominate locations, flows being the new currency in which we should think of all cities as opposed to locations or hubs. Of course we still need to picture cities as sets of structured locations but it is ever more important to think of cities as constellations of flows, not unlike the definitions of the near future, of cyberspace, by Gibson (Gibson, 1884) when he says that (cyberspace) is: "A graphic representation of data abstracted from the banks of every computer in the human system. Unthinkable complexity. Lines of light ranged in the nonspace of the mind, clusters and constellations of data. Like city lights, receding." This is as good a definition of what cities are becoming as any and the kind of science that is needed to progress these ideas is on its way (Batty, 2013).

These changes which will be writ large in a city such as London within the next fifty years, indicate a very different relationship between such large world cities and their hinterlands than anything in the past. London effectively will act - indeed is acting as the global portal for every other city in the UK and perhaps for other cities in its extended global reach. The idea that other big cities should try and compete with London for this reach is problematic, in that this suggests that London (and every other city of this size) is a sensitively-engineered organism whose survival and prosperity depends on a much wider integrated system than one would ever imagine by simply looking at its physical size. In this sense, there is an intrinsic logic to the way globalisation has evolved and it is essential to account for this in any strategy that pits one city against another.

\section{Embedding computers in cities}

In large cities, of which London is the contemporary archetype, the focus is as much on what is happening inside the city with respect to the use of technologies as it is on enabling large cities to become global hubs in the world economy. Computers are being fast embedded into cities to restructure their functioning: to automate urban functions that traditionally were operated largely manually and mechanistically. Instrumentation which enables vehicles and structures to communicate with one another is now becoming widespread. This has happened rather quickly as computers have been miniaturised to the point where they can be embedded into any object. How people communicate and transport themselves, their goods, their information, their ideas, is of course the most obvious of contexts where this has occurred most rapidly. Transport systems where people and vehicles move in regular and routine fashion are now controlled automatically using diverse computer systems whose data is provided from real-time sensing of position and time. We now know where every vehicle and indeed every traveller in the city is, in terms of many well-defined public transport systems, and it is only a matter of time before this will be true for most physical movements. This will potentially create a revolution in how we travel and how we can use information about the system in general to make instant decisions about how to improve our travel experience. Within the next two or three decades, there will be a revolution in the home where all devices that enable us to control the energy we use will be automated through smart metering, which is happening even faster in office and industrial environments. In the short term, as James Martin (Martin, 1978) said more than a generation ago, society and its cities are becoming 'wired' with all the implications for how we might behave in such environments now at the forefront. 
(a)

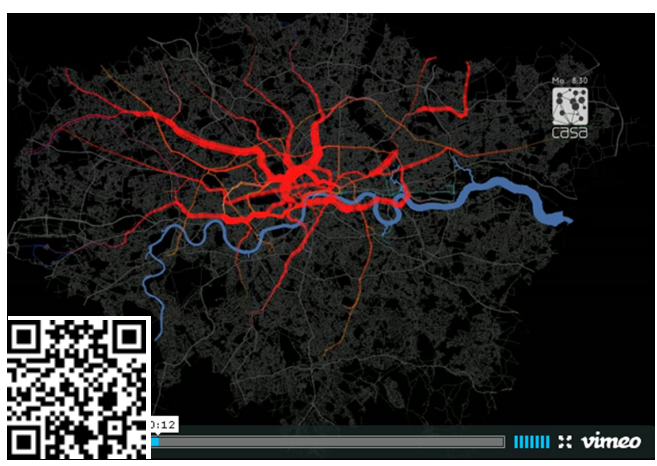

(c)

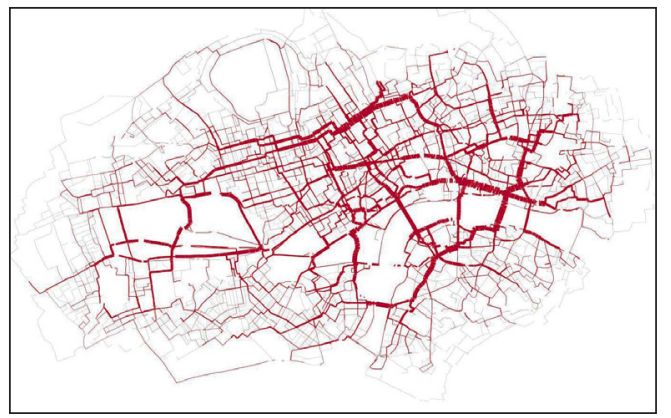

(b)

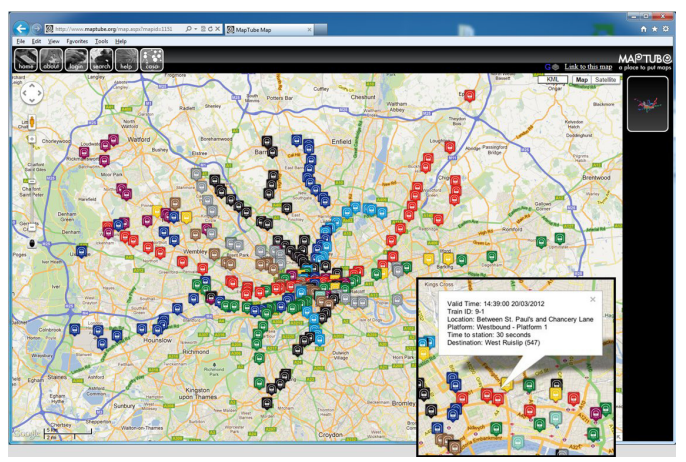

(d)

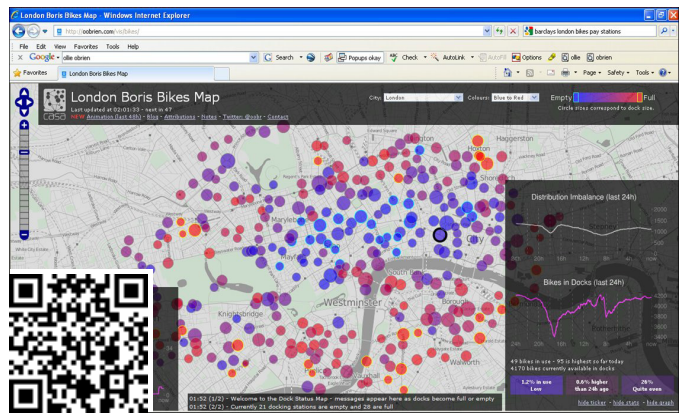

Figure 1: Visualising Smart London 2012.

(a) Public transport flows over one week from Oyster card data. The video by Jon Reades is available at http://dx.doi. org/10.5334/bag.d.1 (or by scanning the QR code in the bottom-left corner); (b) Tube trains in real time (c) Bike flows from the Barclays public bikes scheme. The video of the bike flows from Martin Austwick is available at http://dx.doi. org/10.5334/bag.d.2 (or by scanning the QR code in the bottom-left corner); (d) Bikes in docks at any cross section in time from Ollie O'Brien where you can access up to 100 schemes as well as London and play back animations of the demand and supply of bikes over the last 24 hours http://www.youtube.com/watch?v=NSO4EScYcj8.

There are many examples in present-day London which illustrate how the city is becoming 'smart'. Smart card data from the stored value system called Oyster Card now records all data on where travellers enter the public transport system and leave it. We have months of data on the movements of some six million travellers per day who use the tube and overground rail and we can routinely animate these flows. We also have real-time data from the interfaces that record and communicate information on public transport systems such as bus and rail on the position and delay of any particular vehicle, thus providing us with an instant picture of the supply of public transport at any place and time, as we show in Figure 1(a) for the demand on the tube.

In short, we have data on demand from the Oyster Card and on supply from these interfaces and in principle we should be able to connect these up. In practice, there are enormous problems in doing this because we do not have detailed data on how travellers navigate and use these systems and how long it takes passengers to get on trains, and of course we do not have the actual data relating to individual passengers on trains but in principle we can reconstruct this. Very likely within the decade, we will have much better ways of effecting such integration but at present this is a major obstacle to making these systems smarter. We show the position of the tube trains at a snapshot of time in Figure 1(b) and the challenge faced in linking this data to that shown in Figure 1(a).

The data now extends to public buses and it is a straightforward matter to integrate this with other road traffic volumes. The public bikes scheme in London has been online since its inception in 2010, again illustrated in Figures 1(c) and (d). In fifty years, it is certain that all of this data will 


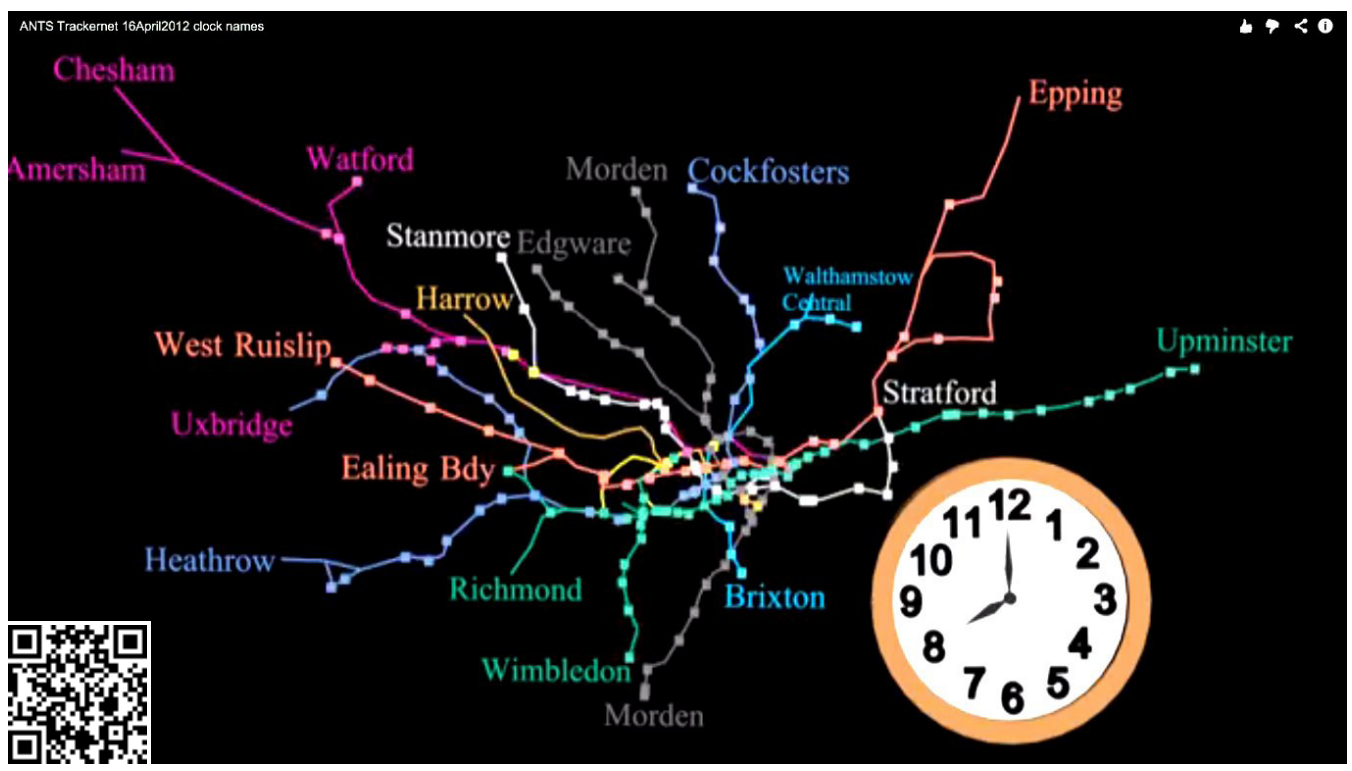

Figure 2: The Flow of Tubes (and Buses) in Real Time.

The animation of the tube trains over a 24 hour period, speeded up of course with some commentary on the data is available at http://dx.doi.org/10.5334/bag.d.3 (or by scanning the QR code in the bottom-left corner).

be integrated and will provide an instant picture of traffic conditions throughout the city. Many other flow systems will be integrated with this such as where pedestrians walk, the locations of hotspots focussing on accidents, crime, access to services, and a host of other data. Integration will remain a problem because these data sets are usually collected either remotely or, if they are related to population attributes, these attributes cannot easily be integrated across different systems. Moreover the technologies themselves are continually undergoing change as are the systems used to collect such data and there is no guarantee that systems such as the ones we now have will continue in the same way into the future. This is a problem of the city becoming too smart for its own sake as new systems take over from those in place, transforming and destroying the data volumes and the experiences that have been gathered so far. These will pose major challenges.

To give an illustration of what will become routine in large cities like London within the next fifty years, if you click on Figure 1(a), you will see the demand for public transport on the tube over a typical week where the movie clearly identifies the weekdays in comparison with the weekends and where the morning, evening and late evening peaks are clearly visible on weekdays. Note however that these data sets show the great heterogeneity of the data from minute to minute as no flow from one day to the next is the same. The same is true of the bikes data in Figure 1(d) where, if you click on the link, the bikes data is animated for a typical 24-hour period just previous to the time when you log onto this web link. In fact we can show some of this data in real time and if you click on Figure 2 you will be taken to a site which shows the animation of this data and thence to a site that shows the movement of tube trains and buses in real time: the tube trains are very slow as they are moving in real time at the scale of the web page and of course they are much bigger on this scale than the map itself simply so we can show them.

This shows London Underground trains for 16 April 2012 between 8am and 8pm using data taken from the TfL Trackernet API. A disruption can be seen between 08:30 and 09:00 when everything stops and then the tubes all re-position themselves. This was caused by an outage in the Trackernet API which feeds us the data. Other anomalies can be seen where tubes move off of the network and then re-join. This occurs where a train is re-positioned part way through its route as 
(a)

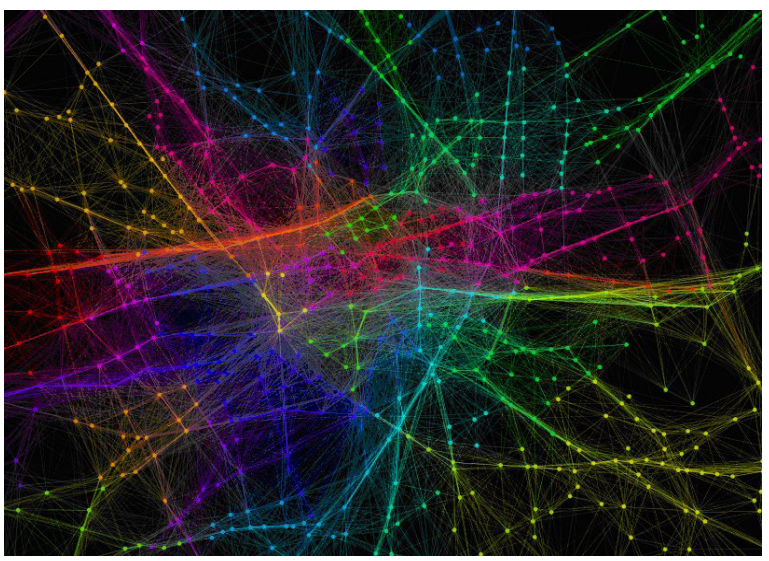

(b)

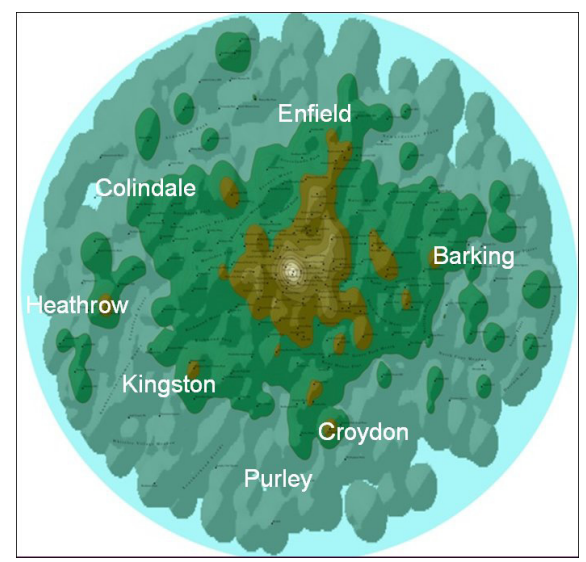

Figure 3: Detecting Location and Network Clusters in Digital Media.

(a) MiniCab routes in central London, where homogenous regions and routes naturally emerge as groups within the dataset, particularly identifying important thoroughfares such as Euston Road, Park Lane and Embankment and areas such as Soho, Shoreditch and Kings Cross; (b) Tweets plotted over 24 hours on a typical weekday in mid 2010 in Inner London, illustrating the tendency for higher densities to define entertainment clusters; data collector software by Steven Gray, and visualization by Fabian Neuhaus (CASA, UCL).

Some animation of tweet data with respect to key locations in the 2012 Jubilee celebrations by Ed Manley are shown at http://www.youtube.com/watch?v=M15Sqw1St1c and http://www.youtube.com/watch?v=2pYP5fiy8Rg. There is a write up in the Guardian newspaper at http://www.theguardian.com/news/datablog/2012/jun/11/queen-s-diamond-jubileetwitter-tweeting.

it disappears from the system for a period of time and then re-appears somewhere else. Although this could have been removed from the animation, it is useful to see where it is happening and has been used to diagnose problems with our tracking system.

The data we get from TfL does not identify the line that a tube is on, so we rely on identification from the location and destination codes. Occasionally, tubes can be misidentified, but the system is adaptive in the sense that it has a limited ability to detect this from the data and modify its destination code table for the next time.

If you want to see the real time web site, please contact Richard Milton (Richard.milton@ucl. ac.uk) who is the author of this but currently the site is not suitable for direct access. In time, it will be and this is something that will be available within the next decade for routine viewing.

There are many new data sets too emerging from all kinds of physical networks transmitting materials and people as well as social media that implies various kinds of social network. In Figure 3(a), we show the communities which can be defined for various kinds of business and related travel from real-time digital data on an up-market limousine (minicab) system in Greater London and this implies how we might use this kind of network data to examine the multiplicity of movement patterns in the city and how these determine locational hotspots. In contrast, in Figure 3(b) we provide a picture of tweets in London over a typical weekday which can be geo-located, giving some sense of the density of tweets with obvious comparisons with related activities and land use clusters. In the future city, in future London, we will see many of these patterns being generated in real time and integrated with one another to give us a new understanding of the way the city functions. In Figure 4, we show the pattern of tweets by language over the summer of 2012 in London, and if you drill down on this, you can zoom into different areas and examine the locations of these languages in detail, comparing your knowledge of what goes on in that part of London with this data. This Twitter data is as good as it gets at present, and language is fairly uncontroversial. It implies location and probably residential 


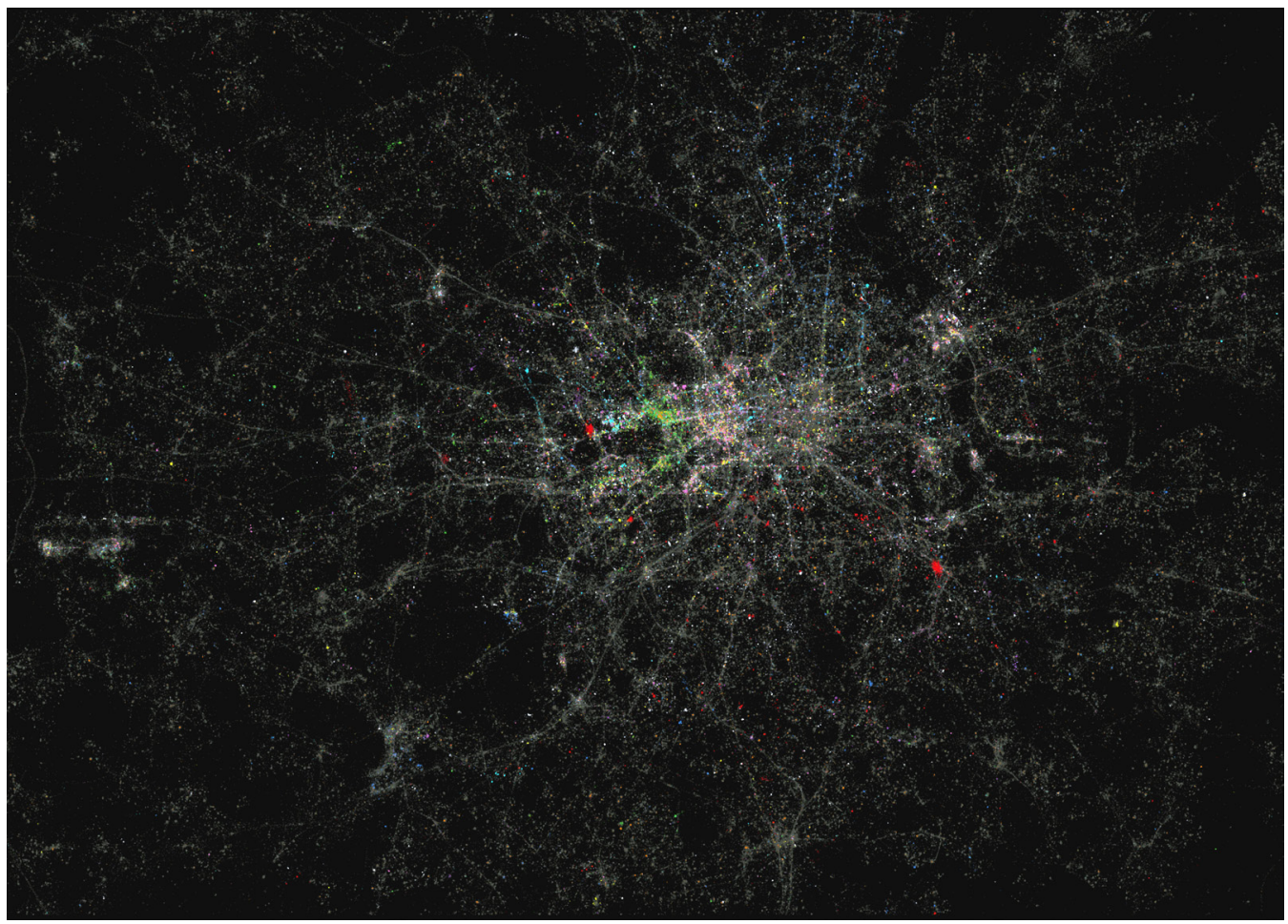

Figure 4: The Twitter Languages of London.

The language of tweets sent from the London area over the summer of 2012. Of 3.3 million tweets, 92.5 per cent are, not surprisingly, in English. The biggest tweeting tongues after that are Spanish (grey), French (red), Turkish (dark blue), Arabic (green), Portuguese (purple), German (orange), Italian (yellow), Malay (turquoise) and Russian (pink). If you drill down you can zoom into the web page where these tweets are easier to locate and identify: http://spatial.ly/2012/10/ londons-twitter-languages/ and at http://twitter.mappinglondon.co.uk/.

location but this kind of social media is presently quite problematic in what it can say about the workings of the city. But it is early days and in time, much more will be possible from this kind of data.

This kind of data that is both a by-product of the smart city and also an essential determinant in making it smarter is changing our perception of cities and producing a much more immediate sense of how a city functions. Big data like this gives us the opportunity of looking at short time scales and this is changing the focus to questions of the short term such as disruptions and disjunctions, to identify differences and hotspots which pertain to good and bad functioning in the city. To an extent, we are currently experiencing rather unusual new forms of data and information which in turn pertain to new kinds of functioning of our physical infrastructures. The great challenge of the next fifty years will be putting in place systems to best exploit these new ideas and to use them to further better the quality of life in cities. Technology is clearly central to the city and the biggest question is: What will places like London look like in fifty years' time? We will close with some speculations.

\section{How smart will London be in 2062?}

If you look back more than half a century to London in the post-war years, technology in the city was very different. In 1946, there were hardly any cars but at least it was widely accepted that cars would become affordable for the majority of the population within a couple of generations. The 
American experience in the 1920s showed that this was possible. However a more revealing statistic was that there were but a handful of computers. Indeed the ten Colossus computers built by post office engineers at Dollis Hill in Northwest London for the code-cracking activities at Bletchley were just being destroyed by a War Office mandate. It took until the mid-1980s for computers to become individually available through the personal computer, and fifty years ago in the early 1960s there was little sense that within a generation the city and the world would be well on the way to being underpinned by widespread computation and the information that this would bring. Back then, the impact of the car on the city was only just beginning to be felt, and even now when computers are everywhere, we are only beginning to grapple with the transformations in physical structures that these will bring in the next fifty years.

The great challenge of course in envisaging London in fifty years' time is in knowing what the balance will be between hardware and software. History suggests that the focus will be entirely on information, that hardware will be writ large but passive and pervasive, but quite what this will mean is hard to grasp. In terms of how it all looks, maybe we will all be wearing Google Glass and sitting in Google Smart Cars. The fact that these exist is an issue but the extent to which they will be all-pervasive is debatable. Reactions against social networks and technologies that are intrusive will be a strong feature of this future and it may well be that some of the science fiction-like technologies such as driverless cars on automated driveways will simply be too difficult to implement. Our experience of building integrated computer and information systems so far has not been good and the difficulties of merging the most obvious data sets such as demand for and supply of travel, as we have indicated above, are legion.

Yet the world we have sketched at present with respect to sensing and big data will massively increase. Imagine then a world, which will not be too long in coming, where all data of this kind can be integrated and accessed and then visualised at any moment, thus providing an immediate picture of how the city functions. Add to this data on energy use in every building, again in real time, and a picture of how sustainable the city is in these terms quickly emerges. Of course, the grand challenge is to make more invisible data on how people relate in terms of their financial transactions accessible, so that we have a much better view of how people and other agencies are engaged in various economic markets such as housing and land. These markets continue to fail to provide the right levels of supply and we urgently need to figure out how capital flows in cities so that we have some sense of where key problems lie. To an extent, such data is becoming available through financial transactions. The Senseable Cities Lab at MIT has visualised credit card transactions over short periods in Spanish cities and there is a well-known web resource for tracking dollar bills in the United States (Batty, 2012). Information which is beginning to substitute as well as complement material flows is much harder to gauge and measure but cities and society now function through such flows. In the next fifty years, we will see enormous strides in measuring information and being able to see how it relates to the space-time functioning of cities. Alongside more visible flows such as transport, this will be the great frontier in enabling our cities to react more effectively to change.

The prospect that there will be much more automation in spatial markets such as housing and really up-to-date information about where populations locate and migrate suggests a future which is much more liquid and volatile than the present, and it is possible that our future concern will be with trying to design into such systems feedback effects for damping such change. Whatever systems emerge, it is clear that we will have a much better picture of real-time populations as they change in space and time over the day, the week, the month and so on and over local to global spaces as people travel and migrate.

Of course in fifty years' time, we will be in a position where much of the data that is now being collected automatically will inform our longer term quest in cities, which involves figuring out traditional problems of where the city is headed. Already we have rudimentary models of how cities function at the aggregate level and recently we have been involved in an integrated assessment 


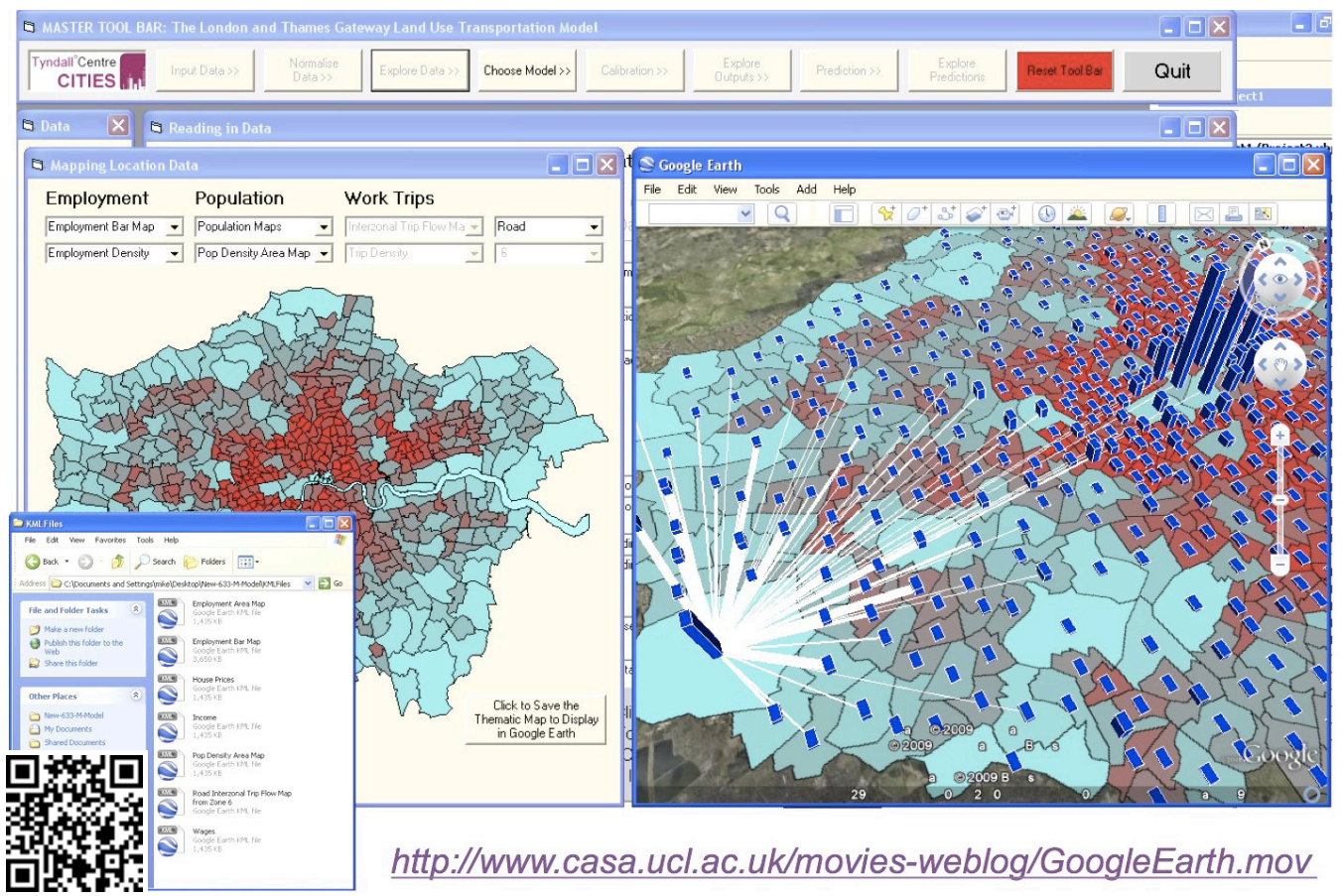

Figure 5: Modelling London 2062 in Real Time?

Our urban model of Greater London can predict locations of future population quickly and graphically. Imagine this kind of forecasting in real time, on-the-fly, continually replenished with new data on a daily basis and accessible anywhere. The only question is whether we want such tools, not whether they are possible. The movie is available at http://dx.doi. org/10.5334/bag.d.4 (or by scanning the QR code in the bottom-left corner).

of the impact of climate change in the London region where the key issue for the next fifty to one hundred years is sea level rise, hence flooding. We have various models that make predictions in small areas of the city where future population and employment will locate (United States Currency Tracking Project, n.d). Fifty years is a long time and no one can pretend to know how we will react in adapting to and mitigating such climate change, but it is now widely accepted that predictive modelling of the kind that has been developed for cities since the 1950s can be used to inform the debate. In London 2062, we imagine that the models we are currently using will be routinely accessible and operational, that we will be examining long-term change on a routine basis, using models of the kind we imply in Figure 5 to inform us continually of how the city is responding and changing. If we think of future London as a moving target, then our models can be updated daily in terms of their data, now from routine sensing, and thence operated in control-room manner in the same way that London and other big cities now manage their traffic systems.

Although what is happening to make the city smarter is largely occurring on a routine basis through new forms of sensing, the next years will be ones where much of this data is integrated. New sources of remotely sensed data will provide daily, or even instant, visualisations of the city and our more abstract scientific models will be integrated in such a way that they become accessible to many more groups of stakeholders. Imagine that each day the data for these models are updated and conditional 'what-if?' scenarios forecast all the time, for short periods of days to speculations about what might happen over the next fifty years. Not only data but also predictions of the many-term futures that the city will face will become available directly on whatever devices we then have to view such information. And as a consequence of this, many, many opportunities will exist for moulding the future city in online forums through various sorts of participation. 
Whether or not we take these up depends on much wider considerations of how we will govern ourselves in an age when whatever we do will be informed by information technologies.

The London of 2062, in terms of how we understand it, will be informed by all these technologies. Given the rate of change in computing since 1962, we cannot begin to imagine what this might actually mean. In fact, although the idea of running models continually and having all this data available for everyone will certainly be feasible, there are still enormous challenges in figuring how all this will play out. Most of all, perhaps, privacy and confidentiality are top of the agenda but we also know that by the year 2062, the problems we will encounter will be very different. Migration is likely to be a major concern while population growth will largely have ended, at least in aggregate terms. We will have passed what Ray Kurzweil calls the singularity (Batty, 2010; Kurzweil, 2006), when medical advances will be integral to the very way we behave and when longevity will be central to the way we figure out how we will live and work. Industrial society and the industrial city will be long gone, but we have little idea of what space and place will then mean. Our models and tools will of course adapt to all of this but what is clear and what we have learned from the last century is that we now know that we will never know the future. Although we might speculate that technologies will be central to this future, London in 2062 will be a very different place functionally, if not physically, from what it is today.

\section{References}

Batty M. 2010. Integrated Models and Grand Challenges. ArcNews. Winter 2010/2011(4): 32. Available from: http://www.esri.com/news/arcnews/winter1011articles/integrated-models.html. [Accessed 2013 August 6]

Batty M. 2012 (28 April). Financial Footprints: Transactions in Real Time. Available from: http:// www.complexcity.info/2012/04/28/financial-footprints-transactions-in-real-time/. [Accessed 6 August 2013]

Batty M. 2013. The New Science of Cities. Cambridge, MA: The MIT Press

Gibson W. 1984. Neuromancer. New York: Ace Books

Kurzweil R. 2006. The Singularity is Near: When Humans Transcend Biology. Penguin Group (USA) Incorporated

Martin J. 1978. The Wired Society: A Challenge for Tomorrow. Englewood Cliffs, NJ: Prentice-Hall Turing AM. 1948. Intelligent Machinery. Teddington, UK: the National Physical Laboratory

United States Currency Tracking Project. N.d. Where's George? Available from: http://www. wheresgeorge.com/. [Accessed 6 August 2013] 


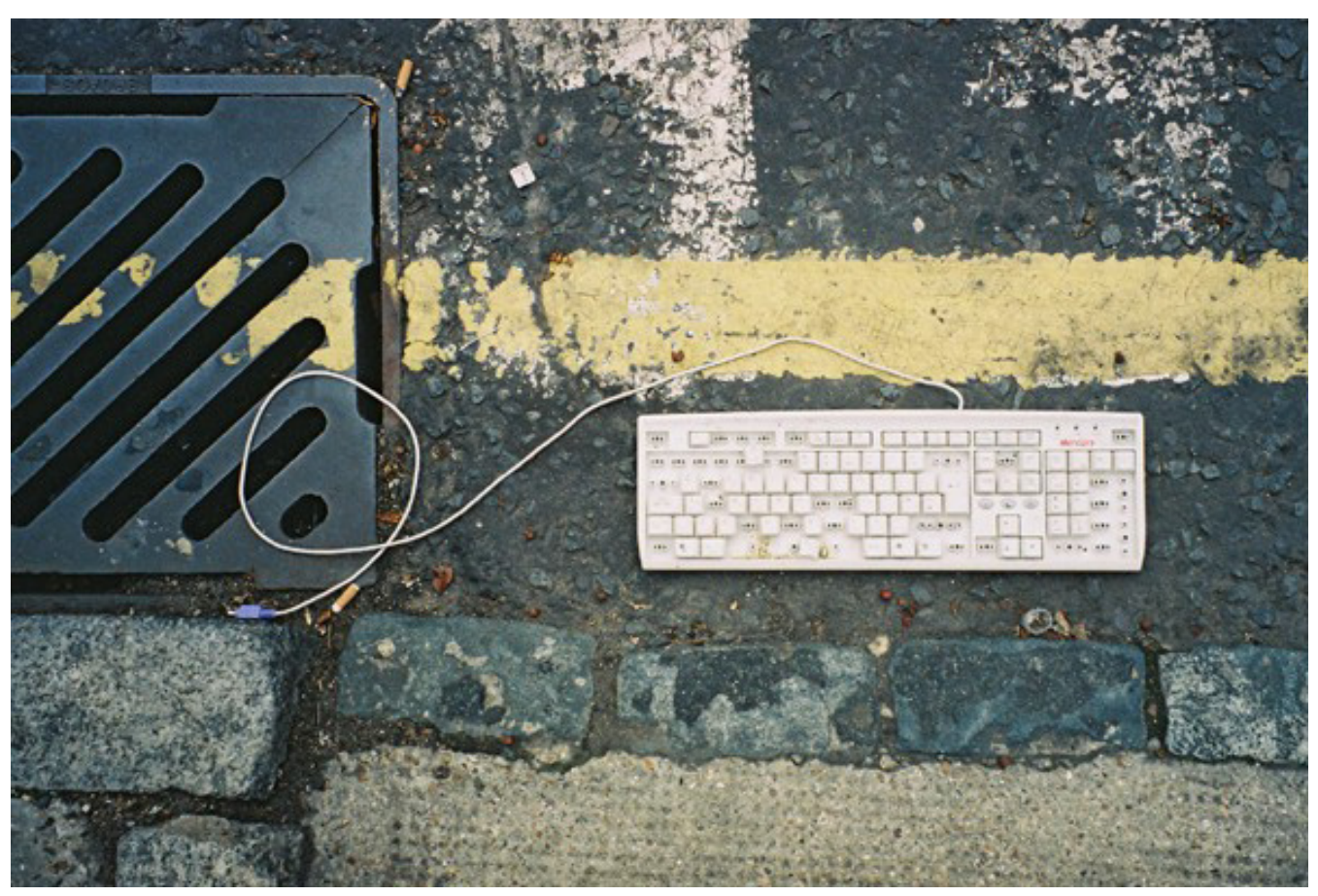

